\title{
THE FUNCTION OF THE ADRENAL GLANDS IN THE NEWBORN*
}

\author{
BY \\ B. WOLMAN \\ From the Department of Child Health, University of Manchester
}

(RECEIVED FOR PUBLICATION OCTOBER 31, 1951)

It is well known that the adrenal cortex of the newborn infant differs anatomically from that of the adult and that morphological changes take place in the gland during the first few days and weeks of extra-uterine life. Until recent times, however, very little had been known about the function of the adrenal cortex during this period and it is questioned whether or not the adrenal, like the kidney, behaves differently from the adult gland at this time. Efforts have been made to study the problem by assaying the excretion of adrenal cortical metabolites in the urine of newlyborn infants and it has been shown that small quantities of such substances not only occur in the first few days of life (Venning, Randall and Gyorgy, 1949; Matson and Longwell, 1949) but also increase significantly in the second week (Read, Venning and Ripstein, 1950). Furthermore the reaction to stress as shown by the response to the administration of epinephrine suggests that the pituitary-adrenal axis is capable of normal function as early as the first day in full-term infants, although prematures do not show this response before the ninth day of life (Jailer, Wong and Engle, 1951). It was therefore considered worth while to study further this problem of adreno-cortical function in the newborn and, as a test of adreno-cortical stimulation, the eosinophil count in the peripheral blood and its response to A.C.T.H. was investigated.

Using Thorn's (1948) test a fall in eosinophils of $50 \%$ or more below the pre-injection level indicates a satisfactory adreno-cortical response and in all probability eliminates the possibility of adrenocortical insufficiency. Although $25 \mathrm{mg}$. A.C.T.H. was described as a suitable test dose for adults, $5 \mathrm{mg}$. was arbitrarily chosen as an adequate stimulus for newborn infants. The eosinophil counts were made on capillary blood obtained by heel prick by the method of Randolph (1949) using the phlox:ne propylene glycol stain. An attempt was made to carry out the second part of the test by estimating the uric acid/creatinine ratio in the urine before and after the injection of

- Paper read at the first English A.C.T.H. Conference at Harroeate on September 13 and 14, 1951 .
A.C.T.H.; although a satisfactory method of collecting urine was established, it was found to be impossible to obtain specimens at the appropriate time intervals, as urine excretion may not take place at all during the first $\mathbf{2 4}$ hours of life.

Twenty-four normal full-term and 11 premature newborn babies were tested in the manner described as soon after birth as possible during the first 24 hours of life, the majority being tested within the first 12 hours. If the test failed to show a $50 \%$ fall in circulating eosinophils, thereby suggesting adreno-cortical insufficiency, it was repeated each 24 hours later until this result was obtained. For control purposes, two eosinophil counts, the second four hours after the first, without the intervening administration of A.C.T.H., were made on 12 normal full term, and six premature, newborn babies during the first and second 24 hours of life.

\section{Results}

Full-term Newborn. Of 24 babies, eight did not give a positive test on the first day of life (Table 1).

TABue 1

Results IN 24 Full-term Newbons

\begin{tabular}{lll|l|l|l|l}
\hline Day of response & $\cdots$ & $\ldots$ & 1st & 2nd & 3rd & 7th \\
\hline Number responding & $\ldots$ & $\ldots$ & 16 & 6 & 1 & 1 \\
\hline
\end{tabular}

With two exceptions (Cases 7 and 13), whose birth weights were over $7 \mathrm{lb}$., all the infants not responding to the test in the first 24 hours weighed less than $6 \frac{1}{2} \mathrm{lb}$. at birth (Table 2).

TABLE 2

Burth Detalls of Ekght Full-Term Newbons Respondng After THE FUST DAY

\begin{tabular}{|c|c|c|}
\hline $\begin{array}{c}\text { Birth } \\
\text { Weight } \\
\text { (Ib. oz.) }\end{array}$ & Mode of Delivery & Day of Response \\
\hline $\begin{array}{rr}7 & 6 \\
5 & 9 \\
7 & 11 \\
6 & 8 \\
5 & 12 \\
6 & 0 \\
6 & 0 \\
6 & 4\end{array}$ & $\begin{array}{l}\text { Normal vertex } \\
\text { Normal vertex } \\
\text { Normal vertex } \\
\text { Caesarean section } \\
\text { Normal vertex } \\
\text { Normal vertex (diabetic mother) } \\
\text { Caesarean section } \\
\text { Normal vertex }\end{array}$ & $\begin{array}{l}\text { Second } \\
\text { Second } \\
\text { Second } \\
\text { Second } \\
\text { Third } \\
\text { Seventh } \\
\text { Second } \\
\text { Second }\end{array}$ \\
\hline
\end{tabular}


Of the eight not responding on the first day, six gave a positive response on the second day.

On the two babies not responding within 48 hours, one, whose birth weight was $5 \mathrm{lb}$. $12 \mathrm{oz}$., the smallest in the series, responded satisfactorily on the third day. The other, whose birth weight was $6 \mathrm{lb}$., did not respond until the seventh day. This infant, the only one in the series taking so long to give a positive test, was the infant of a diabetic mother (Table 3) and was tested on the

TABLE 3

Results in Infait of a Diabetic Mother

\begin{tabular}{c|cc}
$\begin{array}{c}\text { Time } \\
\text { (Hours after birth) }\end{array}$ & $\begin{array}{c}\text { Eosinophils } \\
\text { (per c.mm.) }\end{array}$ & $\begin{array}{c}\text { Blood Sugar } \\
\text { (mg. }\end{array}$ \\
\hline 1 & Under 5 & 51 \\
4 & 180 & 49 \\
19 & Under 5 & 35 \\
23 & 30 & 36 \\
\hline
\end{tabular}

first, second, third, fifth and seventh days of life before a positive response occurred. In fact, on the first four occasions, the eosinophils were less than 5 per c.mm. on initial testing and on three of these four occasions, the administration of $5 \mathrm{mg}$. A.C.T.H. caused an increase in the number of circulating eosinophils four hours later.

Only two other infants showed a low initial count and a slight rise in eosinophils after the injection of A.C.T.H., one being the $5 \mathrm{lb} .12 \mathrm{oz}$. infant mentioned previously and the other a $6 \mathrm{lb} .4 \mathrm{oz}$. infant who responded on the second day.

TARE 4

Day of Response in Relation to Mode of Brth

\begin{tabular}{|c|c|c|c|}
\hline Mode of Birth & $\begin{array}{c}\text { Birth } \\
\text { (lb. }\end{array}$ & $\begin{array}{l}\text { Weight } \\
\text { oz.) }\end{array}$ & Day of Response \\
\hline $\begin{array}{l}\text { Mid forceps } \\
\text { Caesarean section } \\
\text { Caesarean section } \\
\text { Forceps }\end{array}$ & $\begin{array}{l}8 \\
7 \\
6 \\
7\end{array}$ & $\begin{array}{r}3 \\
13 \\
8 \\
1\end{array}$ & $\begin{array}{l}\text { First } \\
\text { First } \\
\text { Second } \\
\text { First }\end{array}$ \\
\hline
\end{tabular}

The mode of birth did not seem to have any effect on the subsequent response to the A.C.T.H. test (Table 4). Two infants born by forceps extraction and one born by Caesarean section responded on the first day, but one other Caesarean baby, whose weight was $6 \mathrm{lb}$. $8 \mathrm{oz}$., did not respond till the second day.

Apart from the infant of the diabetic mother, the initial eosinophil counts ranged from 40 to 1,030 per c.mm., while those of the controls varied from 40 to 820 per c.mm.

Premature Newborns. Of the 12 babies tested (Table 5), four did not give a positive reaction on the first day but responded when tested on the

TABre 5

Results in 12 Pmemature Newborns

$\frac{\text { Day of response }}{\text { Number responding }} \frac{1 \text { st }}{8} \frac{\text { 2nd }}{4}$

second day of life. These four babies showing the delayed response were the smallest babies in the series (Fig. 1). Apart from one premature

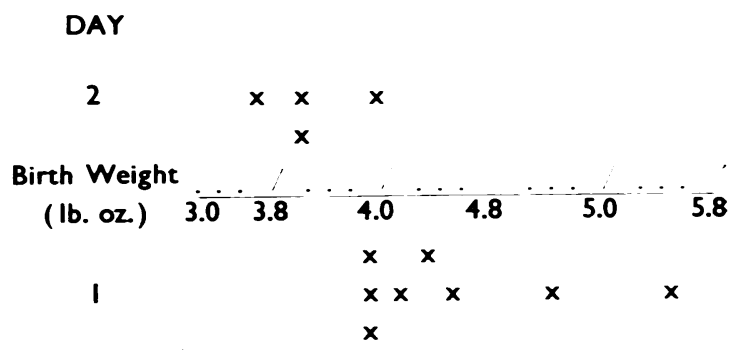

Frg. 1.-Relation of birth weight and day of response in premature newborns.

infant with an eosinophil count of 1,400 per c.mm., the range of eosinophils varied from 10 to 260 per c.mm., and, as in the case of the controls, the values recorded were much lower than those of the normal full-term babies.

Controk. Twelve full-term and six premature newborn babies were not given A.C.T.H. but the eosinophils were counted on two occasions four hours apart on the first day of life. Only two of the 18 babies investigated showed a $50 \%$ decrease in eosinophils when the two counts were compared. Usually the second count equalled or was slightly higher or lower than the first. On no occasion on the second day of life was a $50 \%$ decrease in eosinophils recorded when the two counts were compared.

\section{Discussion}

As a result of this investigation, it would appear that adreno-cortical function as measured by the eosinophil response to A.C.T.H. is normal in the majority of newborn infants on the first day of life. Some infants, in the present series one-third, failed to show normal function during the first 24 hours, but most of these gave a normal response on the second day. The smallest baby in the series, whose birth weight was $5 \mathrm{lb}$. $12 \mathrm{oz}$., did not respond till the third day.

Similarly the majority of premature newborns showed normal adreno-cortical function by this 
test during the first 24 hours of life but the smallest babies in this group, all with birth weights of $4 \mathrm{lb}$. and under, did not give a normal response till the second day of life.

Newborn infants are less sensitive to A.C.T.H. than older ones (Venning et al., 1950) and the small dose, $5 \mathrm{mg}$. of A.C.T.H., used may be the reason for the failure of response on the first day by some of the newborns.

Using the same test of adreno-cortical function in infants during the first and second weeks of life, Klein and Hanson (1950) reported much less response in infants in the first week than there was in infants over one week of age. The observations reported here suggest that adrenocortical function is normal in the majority of fullterm and premature newborns on the first day of life, and the remainder, most of whom are the smaller and more immature, show normal function by the second or third day. These results confirm those of Jailer, Wong and Engle (1951) in America and Bergstrand, Hellström and Jonsson (1951) in Sweden, who found that A.C.T.H. produced eosinopenia in both full-term and premature infants as early as the second or third day of life.

Thus it would appear that although the adrenal cortex is histologically different from that of the adult, it responds in the same way physiologically.

The exception to the foregoing was the infant born of a diabetic mother. This infant continued to show low eosinophil counts during the first week of life and did not develop normal adrenocortical function till the end of the first week. One might speculate that the hypoglycaemia found in this infant after birth and the failure to develop normal adreno-cortical function were interconnected and due to the lack of adreno-cortical hormones. The low eosinophil counts recorded before A.C.T.H. was given might be the response to maternal adrenal steroids, pre-supposing that these cross the placental barrier in a manner similar to gonadotropins and oestrogen, and further work on this type of infant and this aspect of the problem is contemplated.

\section{Summary}

A.C.T.H., 5 mg., was given to 24 full-term and 12 premature newborn infants, and the changes in circulating eosinophils were measured.

Sixteen of the full-term and four of the premature babies showed a normal response as shown by a $50 \%$ decrease in eosinophils on the first day of life.

All but two of the remainder showed a normal response on the second day of life.

One baby, whose birth weight was $5 \mathrm{lb}$. $12 \mathrm{oz}$, responded on the third day, but an infant born of a diabetic mother did not give a normal response till the end of the first week.

It is concluded that although the adrenal cortex is anatomically immature in the first days of life, its function is normal in the majority of newborn and premature babies on the first day and in the remainder on the second day of life.

My thanks are due to Professor Wilfrid Gaisford and Dr. Sylvia K. Guthrie for permission to carry out this investigation in the nurseries at St. Mary's Maternity Hospital, Manchester, and the Premature Unit at the Duchess of York Hospital for Babies, Manchester. The A.C.T.H. was kindly supplied by the Armour Laboratories, Chicago.

\section{REFERENCES}

Bergstrand, C. G., Hellström, B. and Jonsson, B. (1951). Acta paediat., Uppsala, 40, 369.

Jailer, J. W., Wong A. S. H. and Engle, E. T. (1951). J clin.

Klein, R. and Hanson, J. (1950). Pediatrics, 6, 192.

Matson, C. F. and Longwell, B. B. (1949). J. clin. Endocr., 9, 646. Randolph, T. G. (1949). J. Lab. clin. Med., 34, 1696.

Read, C. H., Venning, E. H. and Ripstein, M. P. (1950). J. clin. Endocr., 10, 845

Thorn G. W., Forsham, P. H Prunty, F. T. G. and Hilk, A. G. (1948). J. Amer. med. Ass., 137, 1005. Venning, E. H., Randall, J. P. and Gyorgy, P. (1949). Endocrinologv, 